

\title{
Evidence, and replication thereof, that molecular-genetic and environmental risks for psychosis impact through an affective pathway
}

\author{
Jim van Os ${ }^{1,2,3}$, Lotta-Katrin Pries ${ }^{2}$, Margreet ten Have ${ }^{4}$, Ron de Graaf ${ }^{4}$, Saskia van Dorsselaer ${ }^{4}$, \\ Philippe Delespaul2,5, Maarten Bak ${ }^{2,5}$, Gunter Kenis², Bochao D. Lin ${ }^{6}$, Jurjen J. Luykx ${ }^{1,6,7}$, Alexander L. \\ Richards $^{8}$, Berna Akdede ${ }^{9}$, Tolga Binbay ${ }^{9}$, Vesile Altınyazar ${ }^{10}$, Berna Yalınçetin ${ }^{11}$, Güvem Gümüş- \\ Akay ${ }^{12,13}$, Burçin Cihan ${ }^{14}$, Haldun Soygür ${ }^{15}$, Halis Ulaş ${ }^{16}$, Eylem Şahin Cankurtaran ${ }^{17}$, Semra Ulusoy \\ Kaymak $^{18}$, Marina M. Mihaljevic ${ }^{19,20}$, Sanja Andric Petrovic ${ }^{19,20}$, Tijana Mirjanic ${ }^{19,20}$, Miguel Bernardo ${ }^{21}$ \\ 23, Gisela Mezquida ${ }^{21-23}$, Silvia Amoretti21-23, Julio Bobes ${ }^{23-26}$, Pilar A. Saiz ${ }^{23-26}$, María Paz García- \\ Portilla ${ }^{23-26}$, Julio Sanjuan ${ }^{23,27}$, Eduardo J. Aguilar ${ }^{23,27}$, José Luis Santos ${ }^{23,28}$, Estela Jiménez-López ${ }^{23,29}$, \\ Manuel Arrojo ${ }^{30}$, Angel Carracedo ${ }^{31,32}$, Gonzalo López ${ }^{23,33}$, Javier González-Peñas ${ }^{23,33}$, Mara \\ Parellada ${ }^{23,33}$, Nadja P. Maric ${ }^{19,20}$, Cem Atbaşoğlu ${ }^{34}$, Alp Ucok ${ }^{35}$, Köksal Alptekin ${ }^{9,11}$, Meram Can \\ Saka $^{34}$, Celso Arango ${ }^{23,33}$ Michael O'Donovan ${ }^{8}$, Bart P.F. Rutten ${ }^{2}$, Sinan Guloksuz ${ }^{2,36}$ \\ ${ }^{1}$ Department of Psychiatry, UMC Utrecht Brain Centre, University Medical Centre Utrecht, Utrecht \\ University, Utrecht, The Netherlands \\ ${ }^{2}$ Department of Psychiatry and Neuropsychology, School for Mental Health and Neuroscience, \\ Maastricht University Medical Centre, Maastricht, the Netherlands \\ ${ }^{3}$ Department of Psychosis Studies, Institute of Psychiatry, Psychology \& Neuroscience, King's College \\ London, London, UK \\ ${ }^{4}$ Department of Epidemiology, Netherlands Institute of Mental Health and Addiction, Utrecht, The \\ Netherlands \\ ${ }^{5}$ FACT, Mondriaan Mental Health, Maastricht, Netherlands \\ ${ }^{6}$ Department of Translational Neuroscience, UMC Utrecht Brain Center, University Medical Center \\ Utrecht, Utrecht University, Utrecht, The Netherlands \\ ${ }^{7}$ GGNet Mental Health, Apeldoorn, The Netherlands \\ ${ }^{8} \mathrm{MRC}$ Centre for Neuropsychiatric Genetics and Genomics, Division of Psychological Medicine and \\ Clinical Neurosciences, School of Medicine, Cardiff University, Cardiff, UK \\ ${ }^{9}$ Department of Psychiatry, Faculty of Medicine, Dokuz Eylul University, Izmir, Turkey \\ ${ }^{10}$ Department of Psychiatry, Faculty of Medicine, Adnan Menderes University, Aydin, Turkey \\ ${ }^{11}$ Department of Neuroscience, Graduate School of Health Sciences, Dokuz Eylul University, Izmir, \\ Turkey \\ ${ }^{12}$ Department of Physiology, School of Medicine, Ankara University, Ankara, Turkey \\ ${ }^{13}$ Brain Research Center, Ankara University, Ankara, Turkey \\ ${ }^{14}$ Department of Psychology, Middle East Technical University, Ankara, Turkey \\ ${ }^{15}$ Turkish Federation of Schizophrenia Associations, Ankara, Turkey \\ ${ }^{16}$ Department of Psychiatry, Faculty of Medicine, Dokuz Eylul University, Izmir, Turkey (Discharged by \\ statutory decree No:701 at 8th July of 2018 because of signing "Peace Petition") \\ ${ }^{17}$ Güven Çayyolu Healthcare Campus, Ankara, Turkey \\ ${ }^{18}$ Atatürk Research and Training Hospital Psychiatry Clinic, Ankara, Turkey \\ ${ }^{19}$ Faculty of Medicine, University of Belgrade, Belgrade, Serbia \\ ${ }^{20}$ Institute of Mental Health, Belgrade
}


${ }^{21}$ Barcelona Clinic Schizophrenia Unit, Neuroscience Institute, Hospital Clinic of Barcelona, University of Barcelona, Barcelona, Spain

${ }^{22}$ Institut d'Investigacions Biomèdiques August Pi I Sunyer, Barcelona, Spain

${ }^{23}$ Biomedical Research Networking Centre in Mental Health (CIBERSAM), Spain

${ }^{24}$ Department of Psychiatry, School of Medicine, University of Oviedo, Oviedo, Spain

${ }^{25}$ Instituto de Investigación Sanitaria del Principado de Asturias, Oviedo, Spain

${ }^{26}$ Mental Health Services of Principado de Asturias, Oviedo, Spain

${ }^{27}$ Department of Psychiatry, Hospital Clínico Universitario de Valencia, School of Medicine, Universidad de Valencia, Valencia, Spain

${ }^{28}$ Department of Psychiatry, Hospital Virgen de la Luz, Cuenca, Spain

${ }^{29}$ Universidad de Castilla-La Mancha, Health and Social Research Center, Cuenca, Spain

${ }^{30}$ Department of Psychiatry, Instituto de Investigación Sanitaria, Complejo Hospitalario Universitario de Santiago de Compostela, Santiago de Compostela, Spain

${ }^{31}$ Grupo de Medicina Genómica, Centro de Investigación Biomédica en Red de Enfermedades Raras (CIBERER), Universidad de Santiago de Compostela, Santiago de Compostela, Spain

${ }^{32}$ Fundación Pública Galega de Medicina Xenómica (SERGAS), IDIS, Santiago de Compostela

${ }^{33}$ Department of Child and Adolescent Psychiatry, Institute of Psychiatry and Mental Health, Hospital General Universitario Gregorio Marañón, liSGM, School of Medicine, Universidad Complutense, Madrid, Spain

${ }^{34}$ Department of Psychiatry, School of Medicine, Ankara University, Ankara, Turkey

${ }^{35}$ Department of Psychiatry, Faculty of Medicine, Istanbul University, Istanbul, Turkey

${ }^{36}$ Department of Psychiatry, Yale University School of Medicine, New Haven, CT

Corresponding author:

Jim van Os, Department of Psychiatry, UMC Utrecht Brain Center, University Medical Center Utrecht, PO BOX 85500, 3508 GA Utrecht, The Netherlands. Email: j.j.vanos-2@umcutrecht.nl

Word count: 4522

Tables: 5

Figures: 5

Supplemental material: Yes 


\begin{abstract}
Background. There is evidence that environmental and genetic risk factors for schizophrenia spectrum disorders are transdiagnostic and mediated in part through a generic pathway of affective dysregulation.
\end{abstract}

Methods. We analysed to what degree the impact of schizophrenia polygenic risk (PRS-SZ) and childhood adversity (CA) on psychosis outcomes was contingent on co-presence of affective dysregulation, defined as significant depressive symptoms, in (i) NEMESIS-2 ( $n=6,646)$, a representative general population sample, interviewed four times over nine years and (ii) EUGEI $(n=4,068)$ a sample of patients with schizophrenia spectrum disorder, the siblings of these patients and controls.

Results. The impact of PRS-SZ on psychosis showed significant dependence on co-presence of affective dysregulation in NEMESIS-2 (relative excess risk due to interaction [RERI]: 1.01, $p=0.037$ ) and in EUGEI (RERI=3.39, $\mathrm{p}=0.048$ ). This was particularly evident for delusional ideation (NEMESIS-2: RERI=1.74, $p=0.003$; EUGEI: RERI=4.16, $p=0.019$ ) and not for hallucinatory experiences (NEMESIS-2: $\mathrm{RERI}=0.65, \mathrm{p}=0.284$; EUGEI: $-0.37, \mathrm{p}=0.547)$. A similar and stronger pattern of results was evident for CA (RERI delusions and hallucinations: NEMESIS-2: 3.02, $p<0.001$; EUGEI: $6.44, p<0.001$; RERI delusional ideation: NEMESIS-2: 3.79, $p<0.001$; EUGEI: 5.43, $p=0.001$; RERI hallucinatory experiences: NEMESIS-2: 2.46, p<0.001; EUGEI: 0.54, p=0.465).

Conclusions. The results, and internal replication, suggest that the effects of known genetic and nongenetic risk factors for psychosis are mediated in part through an affective pathway, from which early states of delusional meaning may arise. 


\section{Introduction}

Both genetic and environmental influences increase risk for psychotic disorder. One of the best replicated, non-proxy environmental effects with a relatively large effect size is childhood adversity (CA)(Varese et al., 2012). Molecular genetic analysis of schizophrenia case-control data allows for estimation of a model that predicts trait values from genetic variation, expressed as a polygenic risk score (PRS-SZ), providing a direct measure of schizophrenia genetic risk for analysis (Purcell et al., 2009).

The risk associated with CA and PRS is not specific for psychotic disorder. Around two thirds of genetic associations are common to schizophrenia, bipolar disorder and major depressive disorder and overlap also exists with genetic variants contributing to autism, attention-deficit/hyperactivity disorder, and intellectual disabilities (Cross-Disorder Group of the Psychiatric Genomics et al., 2013, Cross-Disorder Group of the Psychiatric Genomics Consortium, 2019). Therefore, PRS of mental disorders to a large degree represent transdiagnostic risk for mental suffering, particularly the affective spectrum. The level of non-specificity seen for genetic risk also applies to environmental risk factors. CA thus is similarly broadly associated with a range of mental (affective) disorders (Green et al., 2010).

The non-specificity of the most important genetic and environmental risks for psychotic disorder may indicate a shared mechanism of generic mental suffering. This is compatible with epidemiological studies on psychopathology, which have established that the earliest expression of psychosis typically arises within a transdiagnostic mix of symptoms (McGorry and van Os, 2013), particularly depression (Hafner et al., 2005), and that affective dysregulation, particularly depression, is strongly associated with the prevalence and incidence of subthreshold expression of psychotic phenomena in the general population (Guloksuz et al., 2020, van Os and Reininghaus, 2016) as well as with clinical psychotic syndromes (Herniman et al., 2019, Wilson et al., 2020). It has been suggested that affective processes are crucial in the causation of psychosis (Bebbington, 2015, Garety et al., 2005, Krabbendam and van Os, 2005, Upthegrove et al., 2017), as predicted by 
network models of psychosis (Isvoranu et al., 2016), in which genetic and environmental influences impact each other in a dynamic fashion (Guloksuz et al., 2015, Isvoranu et al., 2020, Isvoranu et al., 2017).

These data in combination suggest that although CA and PRS-SZ are strongly associated with schizophrenia spectrum disorder, the mechanism by which they increase risk may be transdiagnostic and mediated in part by a generic pathway of affective dysregulation. If this were true, the impact of CA and PRS on psychosis outcomes would show a degree of dependence on co-occurring affective dysregulation: i.e. is higher if there is additional evidence of affective dysregulation and is lower in the absence of affective dysregulation (Fig. 1). Recent work using indirect measures of genetic risk indeed suggest that this type of relationship exists between (proxy) genetic and environmental risks on the one hand and affective dysregulation on the other in their effects on psychosis outcomes (Pries et al., 2018, Radhakrishnan et al., 2019). However, the hypothesis remains to be tested with direct measures of genetic risk such as PRS-SZ.

In this study, we examined, and attempted to replicate, the hypothesis that the association between PRS-SZ and CA on the one hand, and psychosis outcomes on the other, is contingent, to a degree, on co-presence of significant affective dysregulation. To this end, we examined the interacting contributions of PRS-SZ and CA on the one hand, and affective dysregulation on the other, in models of psychosis in (i) a large population-based cohort $(n=6,646)$ that was examined four times over period of 9 years; and (ii) a large schizophrenia-spectrum case-sibling-control study of 4,068 participants.

Given strong evidence that the terms making up the interactions, PRS-SZ and CA on the one hand, and affective dysregulation on the other, are associated with each other (Brainstorm et al., 2018, Kessler and Magee, 1993, Nivard et al., 2017), the theoretical model of how they work together to affect the outcome of psychosis was considered to be one of mediation, under the framework proposed by Kraemer and colleagues (Kraemer et al., 2001). According to this framework, statistical 
interaction is indicative of moderation if the terms of the interaction are not correlated with each other, and indicative of mediation if the terms of the interaction are correlated with each other. Conceptually, this means that mediation would explain values of $Y$ (psychosis) as indirectly caused by values of $\mathrm{X}$ (genetic and non-genetic aetiology) over a pathway of affective dysregulation.

\section{Method}

Study Populations

\section{NEMESIS-2}

All four waves of the Netherlands Mental Health Survey and Incidence Study-2 (NEMESIS-2) were used. NEMESIS-2 was conducted to study the prevalence, incidence, course, and consequences of mental disorders in the Dutch general population. The baseline data of NEMESIS- 2 were collected from 2007 to 2009, follow-up was until 2018. The study was approved by the Medical Ethics Review Committee for Institutions on Mental Health Care and written informed consent was collected from participants at each wave. To ensure representativeness of the sample in terms of age (between the ages of 18 and 65 at baseline), region, and population density, a multistage random sampling procedure was applied. Dutch illiteracy was an exclusion criterion. Non-clinician, trained interviewers applied the Composite International Diagnostic Interview (CIDI) version 3.0 (Alonso et al., 2004, de Graaf et al., 2008) and additional questionnaires during home visits. Details of NEMESIS-2 are provided elsewhere (de Graaf et al., 2010, de Graaf et al., 2012). The first wave (T0) enrolled 6,646 participants (response rate 65.1\%; average interview duration: 95 minutes), who were followed up in 3 visits within 9 years: successive response rates at year 3 (T1), year 6 (T2), and year 9 (T3) were 80.4\% ( $n=5,303$; excluding those who deceased; interview duration: 84 minutes), 87.8\% ( $n=4,618$; interview duration: 83 minutes), and 86.8\% ( $n=4,007$; interview duration: 102 minutes), respectively. Rates at baseline reflect lifetime occurrence; rates at $\mathrm{T} 1$ to $\mathrm{T} 3$ reflect interval (baseline-T1, T1-T2, and T2-T3) occurrence of approximately 3 years. Attrition between $\mathrm{T}_{0}$ and $\mathrm{T}_{3}$ 
was not significantly associated with any of the mental disorders at $T_{0}$, after controlling for sociodemographic characteristics (de Graaf et al., 2018, Nuyen et al., 2019).

EUGEI

The EUGEI project is a 25-centre, 15-country, EU-funded collaborative network studying the impact of genetic and environmental factors on the onset, course and neurobiology of psychosis spectrum disorder (European Network of National Networks studying Gene-Environment Interactions in Schizophrenia et al., 2014). Workpackage 6, entitled 'Vulnerability and Severity', focussed on the psychometric expression of genetic and environmental liability in the siblings of patients, who are at higher than average genetic and environmental risk compared to healthy comparison participants. The sample in Workpackage 6 was collected in Spain ( 5 centres), Turkey ( 3 centres) and Serbia (1 centre) and consisted of 1,525 healthy comparison participants, 1,261 patients with a diagnosis of psychosis spectrum disorder (average duration of illness since age of first contact with mental health services: 9.9 years) and 1,282 siblings of these patients. Patients were diagnosed with schizophrenia spectrum disorder according to the DSM-IV-TR. This diagnosis was confirmed by the Operational Criteria Checklist for Psychotic and Affective Illness (McGuffin et al., 1991). Exclusion criteria for all participants were diagnosis of psychotic disorders due to another medical condition, history of head injury with loss of consciousness, and intelligence quotient $<70$.

To achieve high quality and homogeneity in clinical, experimental, and environmental assessments, standardized instruments were administered by psychiatrists, psychologists, or trained research assistants who completed mandatory on-site training sessions and online training modules including interactive interview videos and self-assessment tools (European Network of National Networks studying Gene-Environment Interactions in Schizophrenia et al., 2014). Both on-site and online training sessions were repeated annually to maintain high inter-rater reliability throughout the study enrolment period (for details see: https://cordis.europa.eu/result/rcn/175696_en.html). 
The EUGEI project was approved by the Medical Ethics Committees of all participating sites and conducted in accordance with the Declaration of Helsinki. All respondents provided written informed consent and, in the case of minors, such consent was also obtained from parents or legal guardian.

\section{Assessment of psychotic experiences}

In NEMESIS-2, a psychosis add-on instrument based on the $\mathrm{G}$ section of previous CIDI versions was included. This add-on instrument consists of 20 psychotic symptoms corresponding to the symptoms assessed in a previous population survey in the Netherlands, NEMESIS, the precursor of NEMESIS-2 (Bijl et al., 1998, de Graaf et al., 2010). Detailed descriptions of the specific PE items can be found in previous work using NEMESIS (Smeets et al., 2013) and NEMESIS-2 (van Nierop et al., 2012). At baseline, lifetime prevalence of PE was assessed. A clinician did a follow-up telephone interview when participants reported a psychotic symptom to assess whether this symptom was a true PE using questions from the Structured Clinical Interview for DSM-IV. At baseline, a total of 1,081 participants (16.3\%) endorsed at least one self-reported PE. Of these, 794 participated in clinical re-interview (73.5\%), of whom 340 (42.8\%) reported at least one clinically validated PE. At $\mathrm{T} 1,440$ out of a total 5,303 (8.3\%) participants reported that at least one self-reported PE had occurred since the previous interview. Of these, 367 (83.4\%) participants were available for clinical re-interview, of whom 172 (46.9\%) reported at least one clinically validated PE. At T2, 284 out of the total 4,618 (6.2\%) participants reported at least one self-reported PE since the previous interview. Of these, $230(81.0 \%)$ participants were available for clinical re-interview, of which 135 (58.7\%) reported at least one clinically validate PE. At T3, 222 out of the total 4,007 (5.5\%) participants reported at least one self-reported PE since the previous interview. Of these, 207 (93.2\%) participants were available for clinical re-interview, of which 77 (37.2\%) reported at least one clinically validate PE. Given similarities between CIDI self-reported and clinically validated PE, in 
terms of associations, predictive value and outcome (Bak et al., 2003, van der Steen et al., 2019, van Nierop et al., 2012), CIDI self-reported PE were used, thus increasing statistical power.

PE were dichotomized consistent with previous work in NEMESIS and NEMESIS-2 (Pries et al., 2018, Radhakrishnan et al., 2019, van Rossum et al., 2011). Thus, presence of delusions was defined as having at least one delusion endorsed and presence of hallucinations was similarly defined.

In EUGEI, the Community Assessment of Psychic Experiences (Cape; www.cape42.homestead.com) was developed to rate self-reports of lifetime psychotic experiences (Konings et al., 2006). The Cape includes dimensions of positive psychotic experiences, negative experiences and depressive experiences. Effect sizes for internal stability are high, as are correlations between Cape dimensions and conceptually similar dimensions of the Structured Interview for Schizotypy, Revised (Konings et al., 2006, Vollema and Ormel, 2000). Items are modelled on patient experiences as contained in the Present State Examination, 9th version (Wing et al., 1974), schedules assessing negative symptoms such as the Scale for the Assessment of Negative Symptoms (SANS) (Andreasen, 1982) and the Subjective Experience of Negative Symptoms (SENS) (Selten et al., 1993), and scales assessing depressive symptoms such as the Calgary Depression Scale (Addington et al., 1993). Items are scored on a 4-point scale. In the current analyses, Cape dimensions of frequency of positive experiences (20 items), and depressive experiences ( 8 items) were included. A total score representing the mean of all items was calculated for each dimension. For the analyses, conform previous work in this area (Heins et al., 2011, van Dam et al., 2015, van Os et al., 2017), frequency of positive symptoms dichotomized around the $80^{\text {th }}$ percentile in the control group, were used as measures for delusions and hallucinations. Similarly, the frequency score of the 17 Cape delusion items, dichotomized around the $80^{\text {th }}$ percentile in the control group, was used as the delusion outcome. Any presence of hallucinations, as measured by the three Cape hallucination items, was used as the binary hallucination outcome. 


\section{Childhood adversity}

In NEMESIS-2, CA was assessed at TO using a questionnaire based on the NEMESIS trauma questionnaire (de Graaf et al., 2010). Whenever a subject reported having experienced one of five types of childhood adversity before the age of 16 years [emotional neglect (not listened to, ignored, or unsupported), physical abuse (kicked, hit, bitten, or hurt with object or hot water), psychological abuse (yelled at, insulted, unjustly punished/treated, threatened, belittled, or blackmailed), peer victimization (bullying), and one time or more sexual abuse (any unwanted sexual experience)], they were asked to state how often it had occurred on a scale of 1 (once) to 5 (very often). Conforming with previous work in this area, the childhood adversity score was dichotomized at the 80th percentile (Heins et al., 2011, van Dam et al., 2015, van Os et al., 2017).

In EUGEI, childhood adversity was assessed using the Childhood Trauma Questionnaire Short Form (CTQ) that consists of 28 items rated on a 5-point Likert scale measuring five domains of maltreatment (emotional and physical neglect along with emotional, physical, and sexual abuse) (Bernstein et al., 2003). The psychometric characteristics of the translated versions (Spanish, Turkish, Dutch, and Serbian) of the CTQ have been comprehensively studied (Hernandez et al., 2013, Mitkovic-Voncina et al., 2014, Sar et al., 2004, Thombs et al., 2009). Consistent with previous work in similar samples, CTQ score was modelled as a binary variable, calculated around the $80^{\text {th }}$ percentile in the control group (Heins et al., 2011, van Dam et al., 2015, van Os et al., 2017).

\section{Polygenic risk score for schizophrenia}

For details of genotyping and calculation of PRS in NEMESIS-2 and EUGEI we refer to recent papers detailing these procedures (Guloksuz et al., 2019, Pries et al., 2020). We used recent GWASs of schizophrenia (Pardinas et al., 2018) for PRS calculations (Choi et al., 2018). PRS-SZ was created, using the same genotyping platform for EUGEI and NEMESIS-2, from best-estimate genotypes at six different $p$-thresholds $\left(0.5,0.1,0.05,5 \cdot 10^{-3}, 5 \cdot 10^{-5}, 5 \cdot 10^{-8}\right)$. For our primary analyses, we used the 
$p$-threshold of $<0.05$, as this threshold explained most variation in the phenotype in the Psychiatric Genomics Consortium analysis (Schizophrenia Working Group of the Psychiatric Genomics Consortium, 2014). Conform previous analyses in these samples, statistical analyses were adjusted for three and 10 principal components in NEMESIS-2 and EIGEI, respectively (Guloksuz et al., 2019, Pries et al., 2020).

Affective dysregulation

A measure of affective dysregulation was constructed that was comparable across NEMESIS-2 and EUGEI. In NEMESIS-2, depressive symptoms were assessed with the CIDI version 3.0 (Alonso et al., 2004, de Graaf et al., 2008). Affective dysregulation was considered present if participants experienced at least one of the two CIDI 3.0 core symptoms of Depressive Episode, assessed at baseline (assessing lifetime occurrence) and each follow-up visit (assessing interval occurrence). The prevalence of affective dysregulation, thus defined, was $36 \%$.

In EUGEI, Cape frequency of depressive symptoms ( 8 items), dichotomized around the $80^{\text {th }}$ control percentile, was used as the measure for affective dysregulation, conform previous work in this area (Heins et al., 2011, van Dam et al., 2015, van Os et al., 2017).

\section{Statistical analyses}

\section{$\underline{\text { Risk set }}$}

NEMESIS-2

For the childhood adversity analyses, data on childhood adversity, affective dysregulation and psychotic experiences were available for the entire sample with few missing values ( $n=6,643$ at baseline). In the PRS analysis, material for DNA analysis of sufficient quality was available for 3,104 individuals (47\%) at T0 (Pries et al., 2020). Excluding individuals who at interview has been assessed as member of an ethnic minority, given lack of generalizability of PRS to this group, left 3052 for analysis. These 3,052 individuals yielded 9,982 observations with data on psychosis outcomes and 
affective dysregulation at least one of the four interviews. Values for important diagnostic, sociodemographic, familial and environmental risk variables were very similar in a comparison between the 9,982 included and the 9,046 non-included observations (Table 1a).

EUGEI

The EUGEI sample consisted of 4,068 individuals. For the childhood adversity analysis, there were 3,627 participants with complete data for psychosis outcomes, affective dysregulation and childhood adversity (1,491 healthy comparison participants, 1,137 relatives and 999 patients). For the PRS analysis, individuals of non-white ethnic group were excluded, as were individuals with missing GWAS information and missing data on psychosis outcomes and affective dysregulation, leaving 3,088 participants (1,186 healthy comparison participants, 1,001 relatives and 901 patients) for the current analysis. Values for important diagnostic, socio-demographic, familial and environmental risk variables were very similar in a comparison between the 3,088 included and the 934 non-included observations (Table $1 \mathrm{~b})$.

\section{$\underline{\text { Analyses }}$}

All analyses were performed using Stata, version 16 (StataCorp, 2019). $P<0.05$ (2-tailed) was considered nominally statistically significant. Given that in each person contributed multiple observations so that observations were clustered within persons (NEMESIS-2), or that participants were clustered in families (EUGEI), the Stata cluster option was used to take into account intra-group correlations occasioned by clustering of observations within individuals (NEMESIS-2) or families (EUGEI). Models including PRS were adjusted for three principal components (NEMESIS-2) or 10 principal components (EUGEI). Analyses using the EUGEI sample were additionally adjusted for country and for group (control, sibling, patient) using two dummies for siblings status and patient status. 
Given differences between delusions and hallucinations in their patterns of association with other variables (Bartels-Velthuis et al., 2012, Escher et al., 2002, Smeets et al., 2012), three psychosis phenotypes were examined as dependent variable in regression models: delusions and hallucinations (or: psychosis), hallucinations (with or without delusions) and delusions (with or without hallucinations).

Regression models were fitted to examine the hypothesis that the association between affective dysregulation and psychosis would be stronger if PRS-SZ was high. To test this hypothesis, interactions between affective dysregulation and PRS-SZ/CA were tested in models of psychosis phenotypes. Consistent with previous epidemiological analyses with PRS-SZ in this sample, PRS-SZ was examined as a dichotomous variable, using the $75^{\text {th }}$ percentile as cut-off (hereafter: $\mathrm{PRS}_{75}$ ), with sensitivity analyses using a range of cut-offs $(50 \%, 60 \%, 70 \% 80 \%$ and $90 \%$ percentile cut-offs) (Guloksuz et al., 2019). In NEMESIS-2, 75\% cut-offs of the entire population were used; in EUGEI, $75 \%$ percentile cut-offs of the control values were used.

Logistic regression models, taking into account clustering of observations within participants as described above, were applied to test the association between binary affective dysregulation and $\mathrm{PRS}_{75}$ with the three psychosis phenotypes. In testing interaction, additive models were chosen over multiplicative models prior to genetic data collection (EUGEI consortium meeting, December 14, 2013).

To test the joint effects of affective dysregulation and PRS, we entered the four states occasioned by the combination of binary affective dysregulation and binary $\mathrm{PRS}_{75}$ as independent variables (three dummy variables with no-risk state as the reference category), and psychosis phenotype as the dependent variable, in logistic regression models.

We tested for departure from additivity using the interaction contrast ratio, also called the relative excess risk due to interaction (RERI). The RERI is considered the standard measure for interaction on 
the additive scale in case-control studies (Knol and VanderWeele, 2012). The RERI was estimated as (ORaffective dysregulation\&PRS $75-$ ORaffective dysregulation - ORPRS $75+1)($ VanderWeele and Vansteelandt, 2014). A RERI greater than zero was defined as a positive deviation from additivity, and considered significant when the $95 \% \mathrm{Cl}$ did not contain zero. Using the ORs derived from each model, the RERIs for each model were calculated using the delta method (Hosmer and Lemeshow, 1992).

\section{Results}

Distribution of demographic and risk variables are shown in Table 1a (NEMESIS-2) and Table 1b (EUGEI). In both NEMESIS and EUGEI, the terms making up the interactions in the models of psychosis outcomes were positively associated with each other (NEMESIS: PRS and affective dysregulation: $p=0.030 ; C A$ and affective dysregulation: $p<0.001$; EUGEI: PRS and affective dysregulation: $p=0.025 ; C A$ and affective dysregulation: $p<0.001$ ).

In NEMESIS-2, there was evidence that the association between affective dysregulation and psychosis phenotypes was moderated by PRS. This was apparent for the phenotype of delusions and hallucinations (RERI=1.01; $95 \% \mathrm{Cl}: 0.06,1.97)$, and evident for the phenotype of delusions (RERI=1.74, 95\% Cl: $0.58,2.91$ ) but not for hallucinations (RERI=0.65, 95\% Cl: $-0.54,1.85$ )(Table 2, Fig. 2). Similar results were apparent in the EUGEI sample (RERI delusions and hallucinations: 3.39, $95 \% \mathrm{Cl}: 0.03,6.75$; RERI delusions: $4.16,95 \% \mathrm{Cl}$ : 0.69, 7.63; RERI hallucinations: $-0.37,95 \% \mathrm{Cl}:-1.57$, 0.83)(Table 3, Fig. 3).

There was similar and stronger evidence that the association between affective dysregulation and psychosis phenotypes was moderated by CA. In NEMESIS-2, this was evident for all psychosis outcomes (RERI delusions and hallucinations: $3.02,95 \% \mathrm{CI}: 2.04,4.01$; RERI delusions: $3.79,95 \% \mathrm{Cl}$ : 2.59, 5.00; RERI hallucinations: $2.46,95 \% \mathrm{Cl}: 1.21,3.71$ )(Table 4, Fig. 4). Similar results were apparent in EUGEI (RERI delusions and hallucinations: 6.44, 95\% CI: 3.10, 9.78; RERI delusions: 5.43, 95\% Cl: 2.25, 8.61; RERI hallucinations: 0.54, 95\% Cl: -0.90, 1.97)(Table 5, Fig. 5) 
Sensitivity analyses showed results with binary PRS measures were consistent across the different cut-off values (supplemental figures 6 and 7).

\section{Discussion}

Findings

We found, and replicated, that the association between PRS-SZ and childhood adversity on the one hand and psychosis outcomes on the other was contingent on the co-presence of affective dysregulation, which suggests that these risks may be mediated by an affective pathway, through which particularly delusional ideation may arise (Freeman et al., 2013, Garety et al., 2005, Krabbendam and van Os, 2005, Upthegrove et al., 2017). These findings may help explain the nonspecific, transdiagnostic nature of the risk associated with PRS-SZ and CA and the strong connections between affective dysregulation and psychosis across the spectrum of psychotic disorders and the expression of subthreshold psychotic experiences (Hafner et al., 2005, Upthegrove et al., 2017, van Os and Reininghaus, 2016). The findings lend credence to the suggestion by Upthegrove and colleagues, that depression may be "more than comorbidity, and that increased effective therapeutic attention to mood symptoms will be needed to improve outcomes and to support prevention"(Upthegrove et al., 2017). This suggestion concurs with a growing body of literature showing that psychosis arises as a result of worsening non-psychotic affective psychopathology (Guloksuz et al., 2016, Guloksuz et al., 2015, van Rossum et al., 2011) and that the pathway from environmental risk to psychosis involves affective processes (Pries et al., 2018, Radhakrishnan et al., 2019, Reininghaus et al., 2016a, Reininghaus et al., 2016b). Recent research has confirmed that high rates of affective symptoms in early psychosis requires focussed attention on specific therapeutic options for these (Wilson et al., 2020). Potential therapeutic targets may be found in constructs that research suggest may lie at the interface of the dynamics between mood and psychosis such as emotion dysregulation (Liu et al., 2019), level of anticipatory pleasure for future experiences 
(Hallford and Sharma, 2019) and cognitive styles shaping response to early symptoms of affective dysregulation (Rauschenberg et al., 2020, Reininghaus et al., 2019).

\section{Affective dysregulation as a core feature of psychosis}

Much of the focus of research in clinical psychosis syndromes is on the $30 \%$ of patients with a relatively unfavourable prognosis, captured under the diagnosis of 'schizophrenia', of which cognitive dysfunction is considered a core feature (Guloksuz and van Os, 2018, Perala et al., 2007). However, like most measures of psychopathology, cognitive alterations are transdiagnostic (Millan et al., 2012), and cognition in patients with schizophrenia is more strongly associated with polygenic risk that indexes cognitive traits in the general population than polygenic risk from mental disorders (Richards et al., 2019). In other words, lower cognitive ability, distributed in the general population, may predict poorer outcome across mental disorders, which is why it would feature -somewhat tautologically- relatively prominently in the $30 \%$ of patients in the psychosis spectrum presenting with the poorest prognosis. Traditionally, affective dysregulation has received much less attention in research on diagnostic categories like schizophrenia (Garety et al., 2001) even though it has a similar unfavourable effect on outcome (McGinty and Upthegrove, 2020). Review of treatment guidelines indicates a dearth of approaches other than prescription of antidepressant medications (Donde et al., 2018). The current results concur with previous suggestions that affective dysregulation, in particular depression, may be a fundamental feature of psychosis rather than a comorbidity phenomenon (Upthegrove et al., 2017). Indeed, the findings suggest that psychosis spectrum may be best framed as an outcome of developmental vulnerability that can become associated with need for care through an affective pathway. Although this may not be the only pathway, a more formal acknowledgment of the role of affective dysregulation in psychosis it would help to reposition diagnostic framing, treatment focus and research.

The findings also have implications for research, as the association between PRS-SZ and psychosis outcomes may be more productively investigated if stratified by evidence of affective dysregulation. 
Similarly, it is possible that other genetic influences may be more productively uncovered if analyses are stratified by other possible pathways, for example those involving cognitive and motivational factors, that research suggest may also moderate the impact of genetic risk on psychosis outcomes (Pries et al., 2018).

Delusions, Hallucinations and differential mediation by affective dysregulation

The results suggest that if psychosis aetiology in part depends on an affective pathway, this may apply to delusional ideation more than to hallucinatory experiences, particularly as regards genetic aetiology. Main effects were observed for affective dysregulation and CA for all three psychosis outcomes, but not for PRS. In addition, evidence for CA mediation by affective dysregulation was evident for both delusions and hallucinations (although not replicated across both samples), whereas for PRS this was only evident for delusions. These findings suggest a degree of dissociation between genetic and non-genetic aetiological factors in the degree of mediation by affective dysregulation, showing as divergence in results for hallucinations and delusions. It has been suggested that hallucinations may represent the 'primary' experience of aberrant salience that some suggest may be associated with underlying biological mechanisms (Howes and Murray, 2014). Delusional ideation may, to a degree, be secondary to hallucinatory experiences (Krabbendam et al., 2004, Maher, 2006), depending, amongst others, on the level of genetic and non-genetic-induced affective dysregulation (Howes and Murray, 2014, Smeets et al., 2010, Smeets et al., 2015). This may explain why for PRS, in the absence of a main effect on psychosis outcomes, mediation by affective dysregulation was limited to delusions, given the role of emotional biases in the onset of secondary delusions. For CA, the main effect on all psychosis outcomes may either depend more on affective dysregulation, or depend on it in a different fashion, causing it to differ from the pattern of results seen for PRS. However, more work is necessary to verify to what degree the level of affective mediation of genetic aetiology in models of psychosis truly differs between delusions and hallucinations, and what the possible underlying mechanisms of this divergence may be. 
It could also be argued that hallucinations are less prevalent than delusions, resulting in lower power to detect association and thus explaining the divergent findings. However, both in NEMESIS-2 as in EUGEI, the prevalence of delusions and hallucinations as defined for these analyses was approximately similar (NEMESIS-2: $6 \%$ and 5\%, respectively; EUGEI: $25 \%$ and $20 \%$, respectively). In addition, if lack of power was an issue, effect sizes for hallucinations might still be similar to those observed for delusions, which was not the case.

\section{Methodological issues}

Power was low for the analyses with PRS-SZ. The findings suggest that PRS-SZ effect sizes differ as a function of co-presence of affective dysregulation, but this effect was only significant for delusional ideation and effect sizes of PRS-SZ were low. Further replication is therefore required.

Our measure of affective dysregulation was limited to measures of depression. Arguably measures of mania and/or anxiety could have been included, or examined separately for similar interactive effects in the models presented here. Future analyses may address this issue.

Financial support. NEMESIS-2 is conducted by the Netherlands Institute of Mental Health and Addiction (Trimbos Institute) in Utrecht. Financial support has been received from the Ministry of Health, Welfare and Sport, with supplementary support from the Netherlands Organization for Health Research and Development (ZonMw). This work was supported by the European Community's Seventh Framework Program under grant agreement No. HEALTH-F2-2009-241909 (Project EU-GEI). These funding sources had no further role in study design; in the collection, analysis and interpretation of data; in the writing of the report; or in the decision to submit the paper for publication. Bart PF Rutten was funded by a VIDI award number 91718336 from the Netherlands Scientific Organisation. Drs Guloksuz and van Os are supported by the Ophelia research project, ZonMw grant number: 636340001. Dr O'Donovan is supported by MRC programme grant (G08005009) and an MRC Centre grant (MR/L010305/1). 
Conflict of interest. None. 
Table 1a. NEMESIS-2 Sample characteristics, stratified by polygenic risk score risk set included for analysis ( $\mathrm{n}=9,982$ observations) or excluded from analysis ( $\mathrm{n}=9,046$ observations)

\begin{tabular}{|c|c|c|c|c|c|c|c|c|c|c|c|c|c|c|c|c|}
\hline Status & $\mathrm{Del} / \mathrm{Hal}$ & Del & $\mathrm{Hal}$ & $\begin{array}{l}\text { Affective } \\
\text { dysregulation }\end{array}$ & $\begin{array}{l}\text { Family } \\
\text { history }\end{array}$ & $\begin{array}{l}\text { Adversity } \\
\text { score }\end{array}$ & $\begin{array}{l}\text { Cannabis } \\
\text { use }\end{array}$ & Urbanicity & Life events & $\begin{array}{l}\text { Living } \\
\text { alone }\end{array}$ & $\begin{array}{l}\begin{array}{l}\text { Married/Wi } \\
\text { dowed }\end{array} \\
\end{array}$ & Unemployed & Income & $\begin{array}{l}\text { Edu- } \\
\text { cation }\end{array}$ & Age & $\begin{array}{l}\% \\
\text { Female } \\
\end{array}$ \\
\hline & $\%$ & $\%$ & $\%$ & mean & $\%$ & $\%$ & $\%$ & mean & Mean & $\%$ & $\%$ & $\%$ & mean & mean & mean & $\%$ \\
\hline Excluded & 0.1 & 0.06 & 0.05 & 0.37 & 0.52 & 0.54 & 0.02 & 2.98 & 0.72 & 0.22 & 0.63 & 0.13 & 6.9 & 2.99 & 49.15 & 0.54 \\
\hline Sd & & & & 0.48 & & & & 1.35 & 0.92 & & & & 2.48 & 0.9 & $\begin{array}{ll}12.91 \\
\end{array}$ & \\
\hline $\mathrm{N}$ & 9,046 & 8,963 & 9,032 & 9,046 & 9,046 & 9,046 & 8,785 & 9,026 & 8,949 & 9,046 & 9,045 & 9,046 & 8,597 & 9,046 & 9,046 & 9,046 \\
\hline Included & 0.09 & 0.06 & 0.05 & 0.35 & 0.52 & 0.52 & 0.02 & 3 & 0.7 & 0.19 & 0.64 & 0.11 & 7.03 & 3.06 & 48.43 & 0.56 \\
\hline Sd & & & & 0.48 & & & & 1.34 & 0.9 & & & & 2.42 & 0.89 & 12.92 & \\
\hline$N$ & 9,982 & $\begin{array}{l}9,924 \\
\end{array}$ & 9,965 & 9,982 & 9,982 & 9,982 & 9,706 & 9,981 & 9,961 & 9,982 & 9,982 & 9,982 & $\begin{array}{l}9,668 \\
\end{array}$ & $\begin{array}{l}9,982 \\
\end{array}$ & 9,982 & 9,982 \\
\hline Total & 0.09 & 0.06 & 0.05 & 0.36 & 0.52 & 0.53 & 0.02 & 2.99 & 0.71 & 0.2 & 0.63 & 0.12 & 6.97 & 3.03 & 48.77 & 0.55 \\
\hline$S d$ & & & & 0.48 & & & & 1.34 & 0.91 & & & & 2.45 & 0.89 & $\begin{array}{l}12.92 \\
\end{array}$ & \\
\hline $\mathrm{N}$ & 19,028 & 18,887 & 18,997 & 19,028 & 19,028 & 19,028 & 18,491 & 19,007 & 18,910 & 19,028 & 19,027 & 19,028 & 18,265 & 19,028 & 19,028 & 19,028 \\
\hline
\end{tabular}

Del/Hal: CIDI rating delusions or hallucinations

Del: CIDI rating delusions

Hal: CIDI rating hallucinations

Affective dysregulation: at least one of the CIDI 3.0 core symptoms of Depressive Episode

Family history: For participants who screened positive for the following psychiatric diagnoses, presence of the disorder in direct relatives was assessed: alcohol/drugs misuse, depression, mania, and anxiety disorders (panic disorder, social phobia, agoraphobia, generalized anxiety disorder).

Adversity score: total score NEMESIS-2 trauma questionnaire

Cannabis use: use of once or more per week during the lifetime period of most frequent use.

Urbanicity: five levels based on the Dutch classification of increasing population density

Life events: Total score on whether participants had experienced one of 9 life events within the last 12 months (T0) or since the last interview (T1 to T3). Income: net annual household income, rated on a scale from 1 (lowest) to 14 (highest)

Education: 4-level continuous variable (higher level = higher educational level) 
Table 1b. EUGEI sample characteristics, stratified by polygenic risk score risk set included for analysis ( $n=3,088$ participants) or excluded from analysis ( $\mathrm{n}=934$ participants)

\begin{tabular}{|c|c|c|c|c|c|c|c|c|c|c|c|c|c|c|}
\hline Status & $\begin{array}{l}\text { Cape } \\
\text { positive }\end{array}$ & $\begin{array}{l}\text { Cape } \\
\text { delusions }\end{array}$ & $\begin{array}{l}\text { Cape any } \\
\text { hallucination }\end{array}$ & $\begin{array}{l}\text { Cape } \\
\text { depression }\end{array}$ & $\begin{array}{l}\text { CTQ } \\
\text { score }\end{array}$ & $\begin{array}{l}\% \\
\text { Controls }\end{array}$ & $\begin{array}{l}\% \\
\text { Siblings }\end{array}$ & $\begin{array}{l}\% \\
\text { Patients }\end{array}$ & $\begin{array}{l}\text { Cognitive } \\
\text { score }\end{array}$ & $\begin{array}{l}\text { Cannabis } \\
\text { use }\end{array}$ & $\begin{array}{l}\text { Years } \\
\text { education }\end{array}$ & $\begin{array}{l}\text { In a } \\
\text { relationship }\end{array}$ & Age & $\begin{array}{l}\% \\
\text { Female }\end{array}$ \\
\hline & Mean & Mean & $\%$ & Mean & Mean & $\%$ & $\%$ & $\%$ & Mean & $\%$ & Mean & $\%$ & Mean & $\%$ \\
\hline Excluded & 0.35 & 0.4 & 0.16 & 0.63 & 1.48 & 0.35 & 0.28 & 0.37 & 46.86 & 0.11 & 11.25 & 0.64 & 33.56 & 0.45 \\
\hline $\mathrm{sd}$ & 0.38 & 0.42 & 0.36 & 0.48 & 0.44 & & & & 8.7 & & 4.27 & & 9.41 & \\
\hline $\mathrm{N}$ & 563 & 588 & 573 & 573 & 623 & 934 & 934 & 934 & 789 & 811 & 884 & 895 & 934 & 931 \\
\hline Included & 0.36 & 0.39 & 0.2 & 0.66 & 1.49 & 0.38 & 0.32 & 0.29 & 49.01 & 0.12 & 12.19 & 0.69 & 34 & 0.46 \\
\hline$S d$ & 0.39 & 0.41 & 0.4 & 0.49 & 0.45 & & & & 7.99 & & 4.29 & & 9.63 & \\
\hline $\mathrm{N}$ & 3,088 & 3,088 & 3,085 & 3,088 & 3,038 & 3,088 & 3,088 & 3,088 & 2,886 & 2,884 & 3,014 & 3,035 & 3,088 & 3,085 \\
\hline Total & 0.36 & 0.39 & 0.2 & 0.66 & 1.49 & 0.38 & 0.31 & 0.31 & 48.55 & 0.12 & 11.98 & 0.68 & 33.9 & 0.46 \\
\hline $\mathrm{sd}$ & 0.39 & 0.41 & 0.4 & 0.49 & 0.45 & & & & 8.19 & & 4.3 & & 9.58 & \\
\hline $\mathrm{N}$ & 3,651 & 3,676 & 3,658 & 3,661 & 3,661 & 4,022 & 4,022 & 4,022 & 3,675 & 3,695 & 3,898 & 3,930 & 4,022 & 4,016 \\
\hline
\end{tabular}

Cape positive: Cape frequency score positive symptoms

Cape delusions: Cape frequency score delusion items

Cape any hallucination: Any positive rating Cape hallucinations items

Cape depression: Cape depression frequency dimension

CTQ score: CTQ total score

Cognitive score: Z-score, expressed as T-score, of Short version of the WAIS-III short form (Digit Symbol Coding subtest, uneven items of the Arithmetic subtest, uneven items of the Block Design subtest, every third item of the Information subtest (Blyler et al., 2000, Velthorst et al., 2013, Wechsler, 1997). Cannabis use: use of once or more per week during the lifetime period of most frequent use 
Table 2. NEMESIS-2: Risk of psychosis admixture as a function of combinations of binary schizophrenia polygenic risk ( $75^{\text {th }}$ percentile cut-off) and binary affective dysregulation.

\begin{tabular}{|c|c|c|c|c|c|c|}
\hline \multirow{2}{*}{$\begin{array}{c}\text { Phenotype } \\
\text { Delusions and hallucinations }\end{array}$} & \multirow{2}{*}{$\begin{array}{c}\text { Risk } \\
\text { PRS }_{75} \text { only }\end{array}$} & \multirow{2}{*}{$\begin{array}{c}\text { OR } \\
0.87\end{array}$} & \multicolumn{2}{|c|}{$95 \% \mathrm{Cl}$} & \multirow{2}{*}{$\begin{array}{c}P \\
0.369\end{array}$} & \multirow{2}{*}{$\begin{array}{c}N \\
9,982\end{array}$} \\
\hline & & & 0.65 & 1.18 & & \\
\hline & AD only & 3.45 & 2.91 & 4.09 & 0.000 & \\
\hline & $\mathrm{PRS}_{75}+\mathrm{AD}$ & 4.34 & 3.40 & 5.54 & 0.000 & \\
\hline & RERI & 1.01 & 0.06 & 1.97 & 0.037 & \\
\hline \multirow[t]{4}{*}{ Hallucinations } & $\mathrm{PRS}_{75}$ only & 0.94 & 0.63 & 1.41 & 0.778 & 9,965 \\
\hline & AD only & 3.35 & 2.67 & 4.20 & 0.000 & \\
\hline & $\mathrm{PRS}_{75}+\mathrm{AD}$ & 3.95 & 2.81 & 5.53 & 0.000 & \\
\hline & RERI & 0.65 & -0.54 & 1.85 & 0.284 & \\
\hline \multirow[t]{4}{*}{ Delusions } & $\mathrm{PRS}_{75}$ only & 0.74 & 0.50 & 1.08 & 0.123 & 9,924 \\
\hline & AD only & 3.48 & 2.82 & 4.30 & 0.000 & \\
\hline & $\mathrm{PRS}_{75}+\mathrm{AD}$ & 4.96 & 3.78 & 6.51 & 0.000 & \\
\hline & RERI & 1.74 & 0.58 & 2.91 & 0.003 & \\
\hline
\end{tabular}

OR: odds ratio

95\% Cl: 95\% confidence interval

$\mathrm{N}$ : number of observations in analysis

$\mathrm{PRS}_{75}$ : polygenic risk score $75^{\text {th }}$ percentile cut-off

AD: Affective dysregulation (at least one of the two CIDI 3.0 core symptoms of Depressive Episode) RERI: relative excess risk due to interaction 
Table 3. NEMESIS-2: Risk of psychosis admixture as a function of combinations of binary affective dysregulation and binary childhood adversity ( $80^{\text {th }}$ percentile cut-of)

\begin{tabular}{|c|c|c|c|c|c|c|}
\hline Phenotype & Risk & OR & & $6 \mathrm{Cl}$ & $P$ & $\mathrm{~N}$ \\
\hline \multirow{4}{*}{$\begin{array}{l}\text { Delusions and } \\
\text { hallucinations }\end{array}$} & CA only & 2.20 & 1.79 & 2.71 & 0.000 & 20,574 \\
\hline & AD only & 3.36 & 2.97 & 3.80 & 0.000 & \\
\hline & $C A+A D$ & 7.58 & 6.51 & 8.83 & 0.000 & \\
\hline & RERI & 3.02 & 2.04 & 4.01 & 0.000 & \\
\hline \multirow[t]{4}{*}{ Hallucinations } & CA only & 2.76 & 2.11 & 3.60 & 0.000 & 20,537 \\
\hline & AD only & 3.38 & 2.84 & 4.01 & 0.000 & \\
\hline & $C A+A D$ & 7.59 & 6.20 & 9.30 & 0.000 & \\
\hline & RERI & 2.46 & 1.21 & 3.71 & 0.000 & \\
\hline \multirow[t]{4}{*}{ Delusions } & CA only & 1.91 & 1.47 & 2.48 & 0.000 & 20,409 \\
\hline & AD only & 3.54 & 3.04 & 4.12 & 0.000 & \\
\hline & $C A+A D$ & 8.24 & 6.92 & 9.80 & 0.000 & \\
\hline & RERI & 3.79 & 2.59 & 5.00 & 0.000 & \\
\hline
\end{tabular}

OR: odds ratio

95\% Cl: 95\% confidence interval

$\mathrm{N}$ : number of observations in analysis

CA: childhood adversity

AD: Affective dysregulation (at least one of the two CIDI 3.0 core symptoms of Depressive Episode)

RERI: relative excess risk due to interaction 
Table 4. EUGEl: Risk of psychosis admixture as a function of combinations of binary schizophrenia polygenic risk ( $75^{\text {th }}$ percentile cut-off) and binary affective dysregulation (Cape depression $80^{\text {th }}$ percentile)

\begin{tabular}{|c|c|c|c|c|c|c|}
\hline \multirow{2}{*}{$\begin{array}{c}\text { Phenotype } \\
\text { Delusions and hallucinations\# }\end{array}$} & \multirow{2}{*}{$\begin{array}{c}\text { Risk } \\
\mathrm{PRS}_{75} \text { only }\end{array}$} & \multirow{2}{*}{$\begin{array}{r}\text { OR } \\
0.95\end{array}$} & \multicolumn{2}{|c|}{$95 \% \mathrm{Cl}$} & \multirow{2}{*}{$\begin{array}{c}p \\
0.714\end{array}$} & \multirow{2}{*}{$\begin{array}{c}N \\
3,088\end{array}$} \\
\hline & & & 0.71 & 1.27 & & \\
\hline & AD only & 7.34 & 5.70 & 9.45 & 0.000 & \\
\hline & $\mathrm{PRS}_{75}+\mathrm{AD}$ & 10.67 & 7.68 & 14.84 & 0.000 & \\
\hline & RERI & 3.39 & 0.03 & 6.75 & 0.048 & \\
\hline \multirow[t]{4}{*}{ Hallucinations\# } & $\mathrm{PRS}_{75}$ only & 0.85 & 0.62 & 1.18 & 0.335 & 3,085 \\
\hline & AD only & 3.53 & 2.68 & 4.65 & 0.000 & \\
\hline & $\mathrm{PRS}_{75}+\mathrm{AD}$ & 3.01 & 2.10 & 4.32 & 0.000 & \\
\hline & RERI & -0.37 & -1.57 & 0.83 & 0.547 & \\
\hline \multirow[t]{4}{*}{ Delusions\# } & $\mathrm{PRS}_{75}$ only & 0.97 & 0.71 & 1.31 & 0.838 & 3,088 \\
\hline & AD only & 7.32 & 5.67 & 9.46 & 0.000 & \\
\hline & $\mathrm{PRS}_{75}+\mathrm{AD}$ & 11.45 & 8.27 & 15.85 & 0.000 & \\
\hline & RERI & 4.16 & 0.69 & 7.63 & 0.019 & \\
\hline
\end{tabular}

\#: Delusions and hallucinations: Cape positive dimension 80\% control cut-off; Delusions: Cape delusions $80 \%$ control cut-off; Hallucinations: any rating of Cape hallucinations.

OR: odds ratio

95\% Cl: 95\% confidence interval

$\mathrm{N}$ : number of observations in analysis

$\mathrm{PRS}_{75}$ : polygenic risk score $75^{\text {th }}$ percentile cut-off

AD: Affective dysregulation (Cape depression dimension $80 \%$ control cut-off)

RERI: relative excess risk due to interaction 
Table 5. EUGEI: Risk of psychosis admixture as a function of combinations of binary affective dysregulation (Cape depression $80^{\text {th }}$ percentile) and childhood adversity ( $80^{\text {th }}$ percentile cut-off)

\begin{tabular}{|c|c|c|c|c|c|c|}
\hline \multirow{2}{*}{\begin{tabular}{|l|}
\multicolumn{1}{|c|}{ Phenotype } \\
Delusions and \\
hallucinations\#
\end{tabular}} & \multirow{2}{*}{$\begin{array}{c}\text { Risk } \\
\text { CA only }\end{array}$} & \multirow{2}{*}{$\begin{array}{r}\text { OR } \\
2.29\end{array}$} & \multicolumn{2}{|c|}{$95 \% \mathrm{Cl}$} & \multirow{2}{*}{$\begin{array}{r}\text { P } \\
0.000\end{array}$} & \multirow{2}{*}{$\begin{array}{r}N \\
3,627\end{array}$} \\
\hline & & & 1.77 & 2.96 & & \\
\hline & AD only & 6.95 & 5.44 & 8.87 & 0.000 & \\
\hline & $C A+A D$ & 14.67 & 11.38 & 18.92 & 0.000 & \\
\hline & RERI & 6.44 & 3.10 & 9.78 & 0.000 & \\
\hline \multirow[t]{4}{*}{ Hallucinations\# } & CA only & 1.87 & 1.38 & 2.52 & 0.000 & 3,624 \\
\hline & AD only & 3.83 & 2.93 & 5.02 & 0.000 & \\
\hline & $C A+A D$ & 5.24 & 3.97 & 6.90 & 0.000 & \\
\hline & RERI & 0.54 & -0.90 & 1.97 & 0.465 & \\
\hline \multirow[t]{4}{*}{ Delusions\# } & CA only & 2.30 & 1.77 & 2.99 & 0.000 & 3,627 \\
\hline & AD only & 7.40 & 5.78 & 9.46 & 0.000 & \\
\hline & $C A+A D$ & 14.13 & 10.96 & 18.21 & 0.000 & \\
\hline & RERI & 5.43 & 2.25 & 8.61 & 0.001 & \\
\hline
\end{tabular}

\#: Delusions and hallucinations: Cape positive dimension 80\% control cut-off; Delusions: Cape delusions $80 \%$ control cut-off; Hallucinations: any rating of Cape hallucinations.

OR: odds ratio

95\% Cl: 95\% confidence interval

$\mathrm{N}$ : number of observations in analysis

CA: childhood adversity

AD: Affective dysregulation (Cape depression dimension $80 \%$ control cut-off)

RERI: relative excess risk due to interaction 
Fig. 1. Evidence that genetic and environmental risks for psychosis are mediated by an affective pathway: effect sizes will be low if the psychosis outcome is not accompanied by affective dysregulation (left) and effect sizes will be high if affective dysregulation is co-present with the psychosis outcome 
Fig. 2. NEMESIS-2: Additive interaction effects of affective dysregulation (AD) and polygenic risk score for schizophrenia (PRS; 75\% cut-off) in models of psychosis phenotypes; RERI - relative excess risk due to interaction 
Fig. 3. NEMESIS-2: Additive interaction effects of affective dysregulation (AD) and childhood adversity (CA) in models of psychosis phenotypes; RERI - relative excess risk due to interaction 
Fig. 4. EUGEI: Additive interaction effects of affective dysregulation (AD; $80 \%$ cut-off) and polygenic risk score for schizophrenia (PRS; $75 \%$ cut-off) in models of psychosis phenotypes; RERI - relative excess risk due to interaction 
Fig. 5. EUGEl: Additive interaction effects of affective dysregulation (AD; $80^{\text {th }}$ percentile cut-off) and childhood adversity (CA, $80^{\text {th }}$ percentile cut-off) in models of psychosis phenotypes; RERI - relative excess risk due to interaction 
References

Addington D, Addington J \& Maticka-Tyndale E (1993). Assessing depression in schizophrenia: the Calgary Depression Scale. British Journal of Psychiatry Supplement 22, 39-44.

Alonso J, Angermeyer MC, Bernert S, Bruffaerts R, Brugha TS, Bryson H, . . EsemeD/Mhedea Investigators - European Study of the Epidemiology of Mental Disorders Project (2004). Sampling and methods of the European Study of the Epidemiology of Mental Disorders (ESEMeD) project. Acta Psychiatrica Scandinavica Supplementum, 8-20.

Andreasen NC (1982). Negative symptoms in schizophrenia. Definition and reliability. Archives of General Psychiatry 39, 784-8.

Bak M, Delespaul P, Hanssen M, de Graaf R, Vollebergh W \& van Os J (2003). How false are "false" positive psychotic symptoms? Schizophrenia Research 62, 187-9.

Bartels-Velthuis AA, van de Willige G, Jenner JA, Wiersma D \& van Os J (2012). Auditory

hallucinations in childhood: associations with adversity and delusional ideation. Psychological Medicine 42, 583-93.

Bebbington P (2015). Unravelling psychosis: psychosocial epidemiology, mechanism, and meaning. Shanghai Arch Psychiatry 27, 70-81.

Bernstein DP, Stein JA, Newcomb MD, Walker E, Pogge D, Ahluvalia T, . . Zule W (2003).

Development and validation of a brief screening version of the Childhood Trauma Questionnaire.

Child Abuse and Neglect 27, 169-90.

Bijl RV, Ravelli A \& van Zessen G (1998). Prevalence of psychiatric disorder in the general population: results of the Netherlands Mental Health Survey and Incidence Study (NEMESIS). Social Psychiatry and Psychiatric Epidemiology 33, 587-595.

Blyler CR, Gold JM, lannone VN \& Buchanan RW (2000). Short form of the WAIS-III for use with patients with schizophrenia. Schizophrenia Research 46, 209-15.

Brainstorm C, Anttila V, Bulik-Sullivan B, Finucane HK, Walters RK, Bras J, . . Murray R (2018). Analysis of shared heritability in common disorders of the brain. Science $\mathbf{3 6 0}$.

Choi SW, Heng Mak TS \& O’Reilly PF (2018). A guide to performing Polygenic Risk Score analyses. bioRxiv.

Cross-Disorder Group of the Psychiatric Genomics C, Lee SH, Ripke S, Neale BM, Faraone SV, Purcell SM, . . . International Inflammatory Bowel Disease Genetics Consortium (2013). Genetic relationship between five psychiatric disorders estimated from genome-wide SNPs. Nature Genetics 45, 984-94.

Cross-Disorder Group of the Psychiatric Genomics Consortium (2019). Genomic Relationships, Novel Loci, and Pleiotropic Mechanisms across Eight Psychiatric Disorders. Cell 179, 1469-1482 e11. de Graaf R, ten Have M, Burger H \& Buist-Bouwman M (2008). Mental disorders and service use in the Netherlands. Results from the European Study of the Epidemiology of Mental Disorders (ESEMeD) In The WHO World Mental Health Surveys: Global Perspectives on the Epidemiology of Mental Disorders (ed. T. Ustun and R. Kessler), pp. 388-405. Cambridge University Press: New York. de Graaf R, Ten Have M \& van Dorsselaer S (2010). The Netherlands Mental Health Survey and Incidence Study-2 (NEMESIS-2): design and methods. International Journal of Methods in Psychiatric Research 19, 125-41.

de Graaf R, ten Have M, van Gool C \& van Dorsselaer S (2012). Prevalence of mental disorders and trends from 1996 to 2009. Results from the Netherlands Mental Health Survey and Incidence Study2. Social Psychiatry and Psychiatric Epidemiology 47, 203-13.

de Graaf R, van Dorsselaer S, Tuithof M \& ten Have M (2018). Sociodemographic and psychiatric predictors of attrition in the third follow-up of the Netherlands Mental Health Survey and Incidence Study-2 (NEMESIS2). Trimbos Institute: Utrecht. 
Donde C, Vignaud P, Poulet E, Brunelin J \& Haesebaert F (2018). Management of depression in patients with schizophrenia spectrum disorders: a critical review of international guidelines. Acta Psychiatrica Scandinavica 138, 289-299.

Escher S, Romme M, Buiks A, Delespaul P \& van Os J (2002). Formation of delusional ideation in adolescents hearing voices: a prospective study. American Journal of Medical Genetics 114, 913-20. European Network of National Networks studying Gene-Environment Interactions in Schizophrenia, van Os J, Rutten BP, Myin-Germeys I, Delespaul P, Viechtbauer W, . . . Mirjanic T (2014). Identifying gene-environment interactions in schizophrenia: contemporary challenges for integrated, large-scale investigations. Schizophrenia Bulletin 40, 729-36.

Freeman D, Dunn G, Fowler D, Bebbington P, Kuipers E, Emsley R, . . Garety P (2013). Current paranoid thinking in patients with delusions: the presence of cognitive-affective biases.

Schizophrenia Bulletin 39, 1281-7.

Garety PA, Freeman D, Jolley S, Dunn G, Bebbington PE, Fowler DG, ... Dudley R (2005).

Reasoning, emotions, and delusional conviction in psychosis. Journal of Abnormal Psychology 114, 373-84.

Garety PA, Kuipers E, Fowler D, Freeman D \& Bebbington PE (2001). A cognitive model of the positive symptoms of psychosis. Psychological Medicine 31, 189-95.

Green JG, McLaughlin KA, Berglund PA, Gruber MJ, Sampson NA, Zaslavsky AM \& Kessler RC (2010). Childhood adversities and adult psychiatric disorders in the national comorbidity survey replication I: associations with first onset of DSM-IV disorders. Archives of General Psychiatry 67, 113-23.

Guloksuz S, Pries L, ten Have M, de Graaf R, van Dorsselaer S, Klingenberg B, . . van Os J (2020). Association of preceding psychosis risk states and non-psychotic mental disorders with incidence of clinical psychosis in the general population: a prospective study in the NEMESIS-2 cohort. World Psychiatry 19, 199-205.

Guloksuz S, Pries LK, Delespaul P, Kenis G, Luykx JJ, Lin BD, . . van Os J (2019). Examining the independent and joint effects of molecular genetic liability and environmental exposures in schizophrenia: results from the EUGEI study. World Psychiatry 18, 173-182.

Guloksuz S, van Nierop M, Bak M, de Graaf R, Ten Have M, van Dorsselaer S, . . van Os J (2016). Exposure to environmental factors increases connectivity between symptom domains in the psychopathology network. BMC Psychiatry 16, 223.

Guloksuz S, van Nierop M, Lieb R, van Winkel R, Wittchen HU \& van Os J (2015). Evidence that the presence of psychosis in non-psychotic disorder is environment-dependent and mediated by severity of non-psychotic psychopathology. Psychological Medicine 45, 2389-401.

Guloksuz S \& van Os J (2018). The slow death of the concept of schizophrenia and the painful birth of the psychosis spectrum. Psychological Medicine 48, 229-244.

Hafner H, Maurer K, Trendler G, an der Heiden W, Schmidt M \& Konnecke R (2005). Schizophrenia and depression: challenging the paradigm of two separate diseases--a controlled study of schizophrenia, depression and healthy controls. Schizophrenia Research 77, 11-24.

Hallford DJ \& Sharma MK (2019). Anticipatory pleasure for future experiences in schizophrenia spectrum disorders and major depression: A systematic review and meta-analysis. British Journal of Clinical Psychology 58, 357-383.

Heins M, Simons C, Lataster T, Pfeifer S, Versmissen D, Lardinois M, .. . Myin-Germeys I (2011). Childhood trauma and psychosis: a case-control and case-sibling comparison across different levels of genetic liability, psychopathology, and type of trauma. American Journal of Psychiatry 168, 128694.

Hernandez A, Gallardo-Pujol D, Pereda N, Arntz A, Bernstein DP, Gaviria AM, . . . Gutierrez-Zotes JA (2013). Initial validation of the Spanish childhood trauma questionnaire-short form: factor structure, reliability and association with parenting. Journal of Interpersonal Violence 28, 1498-518. 
Herniman SE, Allott K, Phillips L, Wood SJ, Uren J, Mallawaarachchi SR \& Cotton SM (2019).

Depressive psychopathology in first-episode schizophrenia spectrum disorders: a systematic review, meta-analysis and meta-regression. Psychological Medicine 49, 2463-2474.

Hosmer DW \& Lemeshow S (1992). Confidence intervalestimation of interaction. Epidemiology 3. Howes OD \& Murray RM (2014). Schizophrenia: an integrated sociodevelopmental-cognitive model. Lancet 383, 1677-87.

Isvoranu AM, Borsboom D, van Os J \& Guloksuz S (2016). A Network Approach to Environmental Impact in Psychotic Disorder: Brief Theoretical Framework. Schizophrenia Bulletin 42, 870-3.

Isvoranu AM, Guloksuz S, Epskamp S, van Os J, Borsboom D \& Investigators G (2020). Toward incorporating genetic risk scores into symptom networks of psychosis. Psychological Medicine 50, 636-643.

Isvoranu AM, van Borkulo CD, Boyette LL, Wigman JT, Vinkers CH, Borsboom D \& Group Investigators (2017). A Network Approach to Psychosis: Pathways Between Childhood Trauma and Psychotic Symptoms. Schizophrenia Bulletin 43, 187-196.

Kessler RC \& Magee WJ (1993). Childhood adversities and adult depression: basic patterns of association in a US national survey. Psychological Medicine 23, 679-90.

Knol MJ \& VanderWeele TJ (2012). Recommendations for presenting analyses of effect modification and interaction. International Journal of Epidemiology 41, 514-20.

Konings M, Bak M, Hanssen M, van Os J \& Krabbendam L (2006). Validity and reliability of the CAPE: a self-report instrument for the measurement of psychotic experiences in the general population.

Acta Psychiatrica Scandinavica 114, 55-61.

Krabbendam L, Myin-Germeys I, Hanssen M, Bijl RV, de Graaf R, Vollebergh W, . . van Os J (2004). Hallucinatory experiences and onset of psychotic disorder: evidence that the risk is mediated by delusion formation. Acta Psychiatrica Scandinavica 110, 264-72.

Krabbendam L \& van Os J (2005). Affective processes in the onset and persistence of psychosis. European Archives of Psychiatry and Clinical Neuroscience 255, 185-9.

Kraemer HC, Stice E, Kazdin A, Offord D \& Kupfer D (2001). How do risk factors work together? Mediators, moderators, and independent, overlapping, and proxy risk factors. American Journal of Psychiatry 158, 848-56.

Liu J, Chan TCT, Chong SA, Subramaniam M \& Mahendran R (2019). Impact of emotion dysregulation and cognitive insight on psychotic and depressive symptoms during the early course of schizophrenia spectrum disorders. Early Intervention in Psychiatry.

Maher BA (2006). The relationship between delusions and hallucinations. Current Psychiatry Reports 8, 179-83.

McGinty J \& Upthegrove R (2020). Depressive symptoms during first episode psychosis and functional outcome: A systematic review and meta-analysis. Schizophrenia Research 218, 14-27. McGorry P \& van Os J (2013). Redeeming diagnosis in psychiatry: timing versus specificity. Lancet 381, 343-5.

McGuffin P, Farmer A \& Harvey I (1991). A polydiagnostic application of operational criteria in studies of psychotic illness. Development and reliability of the OPCRIT system. Archives of General Psychiatry 48, 764-70.

Millan MJ, Agid Y, Brune M, Bullmore ET, Carter CS, Clayton NS, . . Young $\amalg$ (2012). Cognitive dysfunction in psychiatric disorders: characteristics, causes and the quest for improved therapy. Nature Review Drug Discovery 11, 141-68.

Mitkovic-Voncina M, Lecic-Tosevski D, Pejovic-Milovancevic M \& Popovic-Deusic S (2014). Linking child maltreatment history with child abuse potential: relative roles of maltreatment types. Archives of Biological Sciences 66, 1681-1687.

Nivard MG, Gage SH, Hottenga JJ, van Beijsterveldt CEM, Abdellaoui A, Bartels M, . . Middeldorp CM (2017). Genetic Overlap Between Schizophrenia and Developmental Psychopathology: Longitudinal and Multivariate Polygenic Risk Prediction of Common Psychiatric Traits During Development. Schizophrenia Bulletin 43, 1197-1207. 
Nuyen J, Tuithof M, de Graaf R, van Dorsselaer S, Kleinjan M \& ten Have M (2019). The bidirectional relationship between loneliness and common mental disorders in adults: findings from a longitudinal population-based cohort study. Social psychiatry and psychiatric epidemiology, 1-14. Pardinas AF, Holmans P, Pocklington AJ, Escott-Price V, Ripke S, Carrera N, . . . Walters JTR (2018). Common schizophrenia alleles are enriched in mutation-intolerant genes and in regions under strong background selection. Nature Genetics 50, 381-389.

Perala J, Suvisaari J, Saarni SI, Kuoppasalmi K, Isometsa E, Pirkola S, . . Lonnqvist J (2007). Lifetime prevalence of psychotic and bipolar I disorders in a general population. Archives of General Psychiatry 64, 19-28.

Pries L-K, van Os J, ten Have M, de Graaf R, van Dorsselaer S, Bak M, . . Guloksuz S (2020). Association of recent stressful life events with mental and physical health in the context of genomic and exposomic liability for schizophrenia. JAMA Psychiatry, Published online August 5, 2020.

Pries LK, Guloksuz S, Ten Have M, de Graaf R, van Dorsselaer S, Gunther N, . . van Os J (2018). Evidence That Environmental and Familial Risks for Psychosis Additively Impact a Multidimensional Subthreshold Psychosis Syndrome. Schizophrenia Bulletin.

Purcell SM, Wray NR, Stone JL, Visscher PM, O'Donovan MC, Sullivan PF, . . International Schizophrenia Consortium (2009). Common polygenic variation contributes to risk of schizophrenia and bipolar disorder. Nature 460, 748-52.

Radhakrishnan R, Guloksuz S, Ten Have M, de Graaf R, van Dorsselaer S, Gunther N, . . van Os J (2019). Interaction between environmental and familial affective risk impacts psychosis admixture in states of affective dysregulation. Psychological Medicine 49, 1879-1889.

Rauschenberg C, Reininghaus U, Ten Have M, de Graaf R, van Dorsselaer S, Simons CJP, . . van Os $J$ (2020). The jumping to conclusions reasoning bias as a cognitive factor contributing to psychosis progression and persistence: findings from NEMESIS-2. Psychological Medicine, 1-8.

Reininghaus U, Gayer-Anderson C, Valmaggia L, Kempton MJ, Calem M, Onyejiaka A, . . Morgan C (2016a). Psychological processes underlying the association between childhood trauma and psychosis in daily life: an experience sampling study. Psychological Medicine 46, 2799-813. Reininghaus U, Kempton MJ, Valmaggia L, Craig TK, Garety P, Onyejiaka A, . . Morgan C (2016b). Stress Sensitivity, Aberrant Salience, and Threat Anticipation in Early Psychosis: An Experience Sampling Study. Schizophrenia Bulletin 42, 712-22.

Reininghaus U, Rauschenberg C, Ten Have M, de Graaf R, van Dorsselaer S, Simons CJP, . . van Os $\mathbf{J}$ (2019). Reasoning bias, working memory performance and a transdiagnostic phenotype of affective disturbances and psychotic experiences in the general population. Psychological Medicine 49, 17991809.

Sar V, Akyuz G, Kundakci T, Kiziltan E \& Dogan O (2004). Childhood trauma, dissociation, and psychiatric comorbidity in patients with conversion disorder. Am J Psychiatry 161, 2271-6. Schizophrenia Working Group of the Psychiatric Genomics Consortium (2014). Biological insights from 108 schizophrenia-associated genetic loci. Nature 511, 421-7.

Selten JP, Sijben NE, van den Bosch RJ, Omloo Visser J \& Warmerdam H (1993). The subjective experience of negative symptoms: a self-rating scale. Comprehensive Psychiatry 34, 192-7.

Smeets F, Lataster T, Dominguez MD, Hommes J, Lieb R, Wittchen HU \& van Os J (2010). Evidence That Onset of Psychosis in the Population Reflects Early Hallucinatory Experiences That Through Environmental Risks and Affective Dysregulation Become Complicated by Delusions. Schizophrenia Bulletin.

Smeets F, Lataster T, Dominguez MD, Hommes J, Lieb R, Wittchen HU \& van Os J (2012). Evidence that onset of psychosis in the population reflects early hallucinatory experiences that through environmental risks and affective dysregulation become complicated by delusions. Schizophrenia Bulletin 38, 531-42.

Smeets F, Lataster T, van Winkel R, de Graaf R, Ten Have M \& van Os J (2013). Testing the hypothesis that psychotic illness begins when subthreshold hallucinations combine with delusional ideation. Acta Psychiatrica Scandinavica 127, 34-47. 
Smeets F, Lataster T, Viechtbauer W, Delespaul P \& G.R.O.U.P (2015). Evidence that environmental and genetic risks for psychotic disorder may operate by impacting on connections between core symptoms of perceptual alteration and delusional ideation. Schizophrenia Bulletin 41, 687-97.

StataCorp (2019). STATA Statistical Software: Release 16. College Station: Texas.

Thombs BD, Bernstein DP, Lobbestael J \& Arntz A (2009). A validation study of the Dutch Childhood Trauma Questionnaire-Short Form: factor structure, reliability, and known-groups validity. Child Abuse and Neglect 33, 518-23.

Upthegrove R, Marwaha S \& Birchwood M (2017). Depression and Schizophrenia: Cause, Consequence, or Trans-diagnostic Issue? Schizophrenia Bulletin 43, 240-244.

van Dam DS, van Nierop M, Viechtbauer W, Velthorst E, van Winkel R, Genetic R, . . Wiersma D (2015). Childhood abuse and neglect in relation to the presence and persistence of psychotic and depressive symptomatology. Psychological Medicine 45, 1363-77.

van der Steen $Y$, Myin-Germeys I, van Nierop M, Ten Have M, de Graaf R, van Dorsselaer S, . . van Winkel R (2019). 'False-positive' self-reported psychotic experiences in the general population: an investigation of outcome, predictive factors and clinical relevance. Epidemiology and Psychiatric Sciences 28, 532-543.

van Nierop M, van Os J, Gunther N, Myin-Germeys I, de Graaf R, ten Have M, . . van Winkel R (2012). Phenotypically continuous with clinical psychosis, discontinuous in need for care: evidence for an extended psychosis phenotype. Schizophrenia Bulletin 38, 231-8.

van Os J, Marsman A, van Dam D, Simons CJ \& Investigators G (2017). Evidence That the Impact of Childhood Trauma on IQ Is Substantial in Controls, Moderate in Siblings, and Absent in Patients With Psychotic Disorder. Schizophrenia Bulletin 43, 316-324.

van Os J \& Reininghaus U (2016). Psychosis as a transdiagnostic and extended phenotype in the general population. World Psychiatry 15, 118-24.

van Rossum I, Dominguez MD, Lieb R, Wittchen HU \& van Os J (2011). Affective dysregulation and reality distortion: a 10-year prospective study of their association and clinical relevance.

Schizophrenia Bulletin 37, 561-71.

VanderWeele TJ \& Vansteelandt S (2014). Invited commentary: Some advantages of the relative excess risk due to interaction (RERI)--towards better estimators of additive interaction. American Journal of Epidemiology 179, 670-1.

Varese F, Smeets F, Drukker M, Lieverse R, Lataster T, Viechtbauer W, . . Bentall RP (2012).

Childhood adversities increase the risk of psychosis: a meta-analysis of patient-control, prospectiveand cross-sectional cohort studies. Schizophrenia Bulletin 38, 661-71.

Velthorst E, Levine SZ, Henquet C, de Haan L, van Os J, Myin-Germeys I \& Reichenberg A (2013). To cut a short test even shorter: reliability and validity of a brief assessment of intellectual ability in schizophrenia--a control-case family study. Cognitive Neuropsychiatry 18, 574-93.

Vollema MG \& Ormel J (2000). The reliability of the structured interview for schizotypy-revised. Schizophrenia Bulletin 26, 619-29.

Wechsler D (1997). WAIS-III: Wechsler Adult Intelligence Scale (3rd ed.) Administration and Scoring Manual. Psychological Corporation: San Antonio, TX.

Wilson RS, Yung AR \& Morrison AP (2020). Comorbidity rates of depression and anxiety in first episode psychosis: A systematic review and meta-analysis. Schizophrenia Research 216, 322-329.

Wing JK, Cooper JE \& Sartorius N (1974). The measurement and classification of psychiatric symptoms. Cambridge University Press: London. 